\title{
Los litograbados de la iglesia de Matara, Antabamba-Apurímac
}

Artículos originales: ANTROPOLOGÍA

Recibido: 28/04/2021

Aprobado: 12/06/2021

Publicado: 14/10/2021

\author{
Raúl Carreño-Collatupa \\ Grupo Ayar, Cusco \\ raulcarreno@ayar.org.pe
}

\begin{abstract}
RESUMEN
Nueve litograbados fueron identificados en la escalinata del arco de acceso al conjunto eclesiástico de Matara, en la provincia de Antabamba, Apurímac, todos con figuraciones abstractas e incisos en roca andesítica. Por la naturaleza de su iconografía, el hecho de que los grabados están cortados y en sillares incorporados a una construcción inka (huaka) primero y, posteriormente, a un conjunto eclesiástico colonial, es innegable que estos litos son atribuibles a tiempos pre-inkas y que el de la iglesia de Matara es un contexto rupestre secundario. Hasta donde se conoce, son los primeros litograbados registrados en la provincia de Antabamba, donde sólo se conocían pictografías. Lamentablemente, la mayoría de ellos han desaparecido en los últimos años debido a una «modernización» emprendida por las autoridades municipales de Matara y Huaquirca.
\end{abstract}

Palabras Clave: arte rupestre, litograbado, Matara, Antabamba, Apurímac.

\section{Petroglyphs of church of Matara, Antabamba-Apurímac}

\begin{abstract}
Nine petroglyphs were identified on a stairway located in the access arch to the Matara ecclesiastical complex, Antabamba province, Apurimac, all of them containing abstract figurations engraved on the andesitic rock. Due to the nature of its iconography, the fact that pre-inka engravings cut as ashlars, incorporated to an Inka structure (huaka $=$ shrine) and, subsequently, to a colonial ecclesiastical complex, it is undeniable that these petroglyphs are pre-inka belonging to a secondary context. As far as it is known, they are the first petroglyphs registered in Antabamba province, where only pictographs were previously known. Unfortunately, most of them have disappeared in recent years due to a wrong 'modernization' concept undertaken by the municipal authorities of Matara and Huaquirca.
\end{abstract}

KEYwORDs: rock art, petroglyph, Matara, Antabamba, Apurímac. 


\section{Introducción}

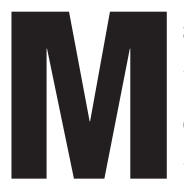
atara —específicamente su iglesia- es un sitio rupestre con litograbados que, en su mayoría, han desaparecido en los últimos años, probablemente por latrocinio, o por haber sido tirados como desmonte o incorporados a estructuras de concreto. Esta situación es doblemente grave, por cuanto, hasta donde se tiene referencia, estos eran los primeros litograbados identificados en la provincia de Antabamba, donde anteriormente sólo se habían registrado sitios con pictogramas.

Gracias a registros fotográficos realizados en 2008 y 2010 se ha podido guardar referencia de estos grabados (y de todo su entorno arquitectónico que involucraba elementos precolombinos y coloniales), cuya desaparición implica, además de un atentado cultural, la pérdida de una referencia importante para futuros estudios arqueológicos de la zona, especialmente en lo referido al establecimiento de filiaciones y correlaciones culturales, esenciales para una región cuyo pasado es aún poco conocido y escasamente investigado.

\section{Matara}

El pueblo de Matara, situado a una altitud de 3369 msnm y a unos $5.5 \mathrm{~km}$ al ONO de la capital provincial (fig. 1), es el único anexo del distrito de Huaquirca, provincia de Antabamba, departamento de Apurímac. Su población apenas ha variado a lo largo de los siglos: 180 personas en el 2010 (DNTDT, 2012: 30), casi la misma que tenía en 1786 (160 habitantes, según el informe de Benito Mata Linares). Cabe anotar que en el período intercensal 20072007, la provincia de Antabamba sufrió una pérdida de población de -7.8\% (INEI, 2018: 24), algo que ha debido de repercutir en todos sus distritos. Por su laguna y su gran islote de totora, por su entorno paisajístico y por su magnífica posición sobre el valle, el pueblo es conocido como "la perla de Antabamba» (fig. 2).

Matara es un pueblo antiguo y, como hoy, siempre fue un anexo de Huaquirca. Según el muy detallado informe de Joseph Arias de Torres y Sanabria, "cura propio y Vicario de la Doctrina del pueblo de

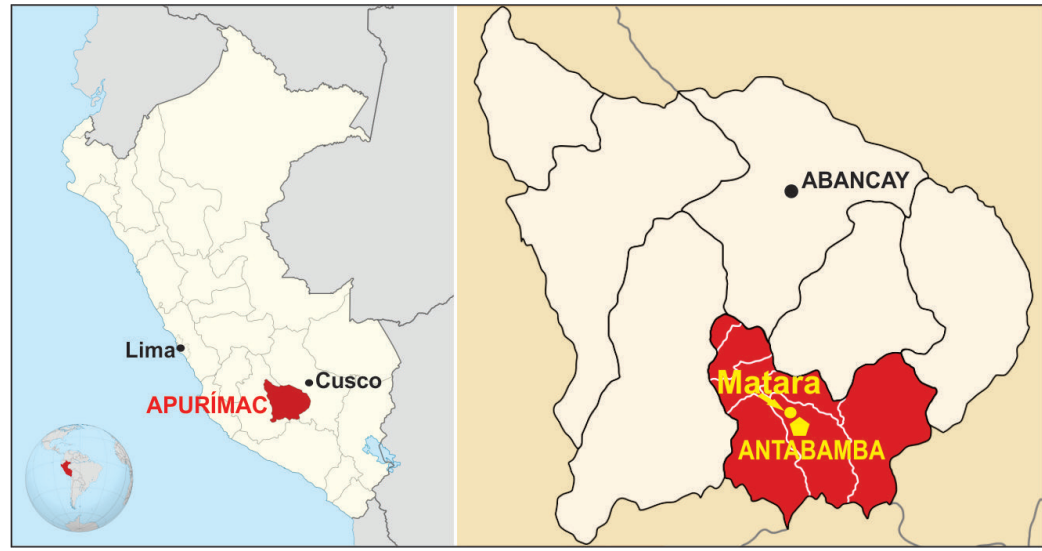

Fig. 1. Ubicación de Matara

nra. Sa. de la Asumpcion de Guaquirca Provincia de los Aimaraes», enviado a Manuel de Mollinedo y Angulo, obispo del Cusco, el 26 de septiembre de 1689, Huaquirca tiene «un anejo que se intitula Sn. Pedro Truxillo de Matara, que aviendo sido el mas principal y cavesera deste repartimiento de Collana Aymaraes y el primer curato que ubo y se componía de veinte y dos ayllos» y que el pueblo «esta en medio de tres curatos»: Antabamba, Mollebamba y Sabaino (Villanueva, 1982: 392-393). Al parecer Matara fue perdiendo importancia con el tiempo, pues de primera parroquia con 22 ayllus en la segunda mitad del siglo XVI pasó a la categoría de anexo con sólo dos ayllus a fines del siglo XVII. Lo mismo pasó en general con Huaquirca, su cabeza de doctrina y actual capital del distrito; Garcilaso (1609: 66) refiere que «oy tiene más de dos mil casas» y que era parte «de la misma prouincia Aymara», que fue conquistada por el Inka Qhapaq Yupanki (Capac Yupanqui), quinto emperador del Cusco; al principio los aymaras o aymaraes opusieron resistencia, pero luego se sometie-

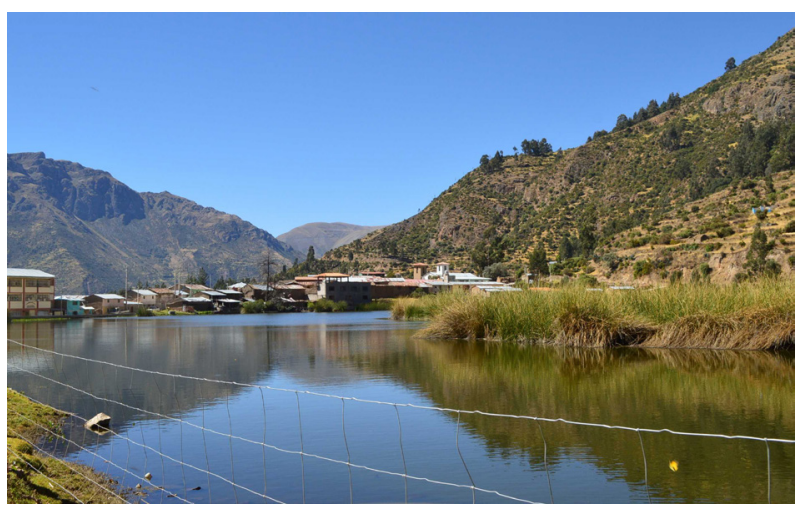

Fig. 2. Vista del pueblo de Matara y su laguna 
ron a los cusqueños con la condición de que el Inka los librara de los abusos que cometían contra ellos los umasuyus (omasuyos), "gente belicosa y tirana", según Garcilaso, que dominaban la vecina cuenca del río Vilcabamba (hoy provincia de Grau, aunque la parte superior pertenece a Antabamba) y parte de Cotabambas. Para tal cometido, el ejército imperial hizo de Huaquirca su base de operaciones logrando derrotar a los umasuyus. Como las disputas eran principalmente por pastos, Qhapaq Yupanki mandó hacer «el deslinde de tierras y pastos entre Aymaras y Omasuyos, con mojoneras por las que se guardó gran veneración» (Sánchez Garrafa, 1999: 26).

\section{La iglesia de San Pedro de Matara}

A partir del mencionado testimonio de Arias de Torres enviado en 1689, se deduce que la iglesia de Matara fue la primera construida en la zona, infiriéndose que ya existía en 1613, por cuanto un documento del Archivo Arzobispal del Cusco consigna que ese año el pueblo era atendido por clérigos (Viñuales y Gutiérrez, 2014: 153), lo cual implica la existencia de un templo. El edificio se erigió, al parecer, sobre un ushnu, tipo de estructura no muy frecuente en la provincia de Antabamba, como parte de la muy conocida práctica de reemplazar huakas o adoratorios prehispánicos por ermitas, capillas o iglesias cristianas. El templo estuvo originalmente bajo la advocación de san Pedro y san Pablo, pero éste último ha sido siempre ignorado; de cualquier modo, la fiesta principal del pueblo es la consagrada a Santa Rosa de Lima. El testimonio de 1689, que alude a un San Pedro de Truxillo, plantea una duda importante acer- ca de a qué se refiere el agregado de "Truxillo", pues no hay en el santoral un santo con esa nominación.

El templo es «de una sola nave, aunque se ve que hubo la intención de dotarla de un crucero [...] Las paredes son gruesas construcciones de mampostería de piedra, con contrafuertes y otros muretes de contención que parecen agregados en diferentes épocas, algunos de los cuales se colocan diagonalmente» (Viñuales y Gutiérrez, 2014: 155). Un documento de 1836 advierte sobre el lamentable estado de conservación del templo; esto respondió al hecho de que el Estado de la joven república retiró los subsidios a la iglesia, por lo que el clero se vio obligado a abandonar la región (Gose, 2004: 57). Ya en los informes remitidos al obispo Mollinedo en 1689, casi todos los párrocos daban cuenta de la pobreza de recursos de sus curatos, que en promedio tenían medio topo de maíz para sostenerse. En 1841 se emprendieron trabajos de restauración, realizados con bastante lentitud, hasta que en 1843 los carpinteros Tomás Collado y Asencio Mallma rehacen el techo y en 1846 Martín Coronado, «vecino de Caraybamba», restaura el retablo mayor (Vińuales y Gutiérrez, 2014: 154).

En los últimos diez años, las autoridades municipales de Matara y Huaquirca han cometido una serie de deplorables actos vandálicos bajo el disfraz de una pretendida "modernización» del pueblo, por el cual muchas muestras de arquitectura tradicional han sido demolidas, como los dos arcos de acceso de adobe y piedra — que definían la identidad del pueblo-, muchas casas antiguas, el antiguo cementerio, la casa cural, parte del cerco de contorno, el túnel que comunicaba el atrio de la iglesia con la plaza de toros situada en el parque vecino, invadiendo además la plaza-atrio de la iglesia con construcciones de

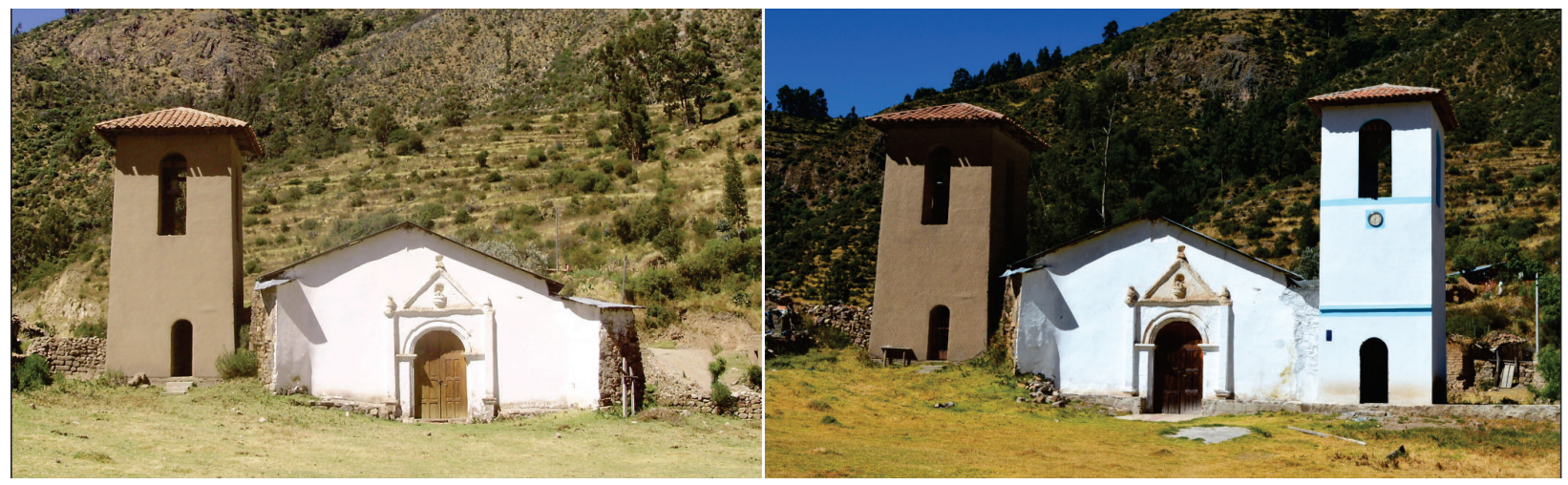

Fig. 3. La iglesia de Matara en mayo 2008 y en julio 2019 
concreto absolutamente discordantes con el entorno arquitectónico original. Para completar este desolador panorama, se ha agregado una torre que nunca existió, y no se trata de una restitución, pues los testimonios históricos, desde el siglo XVII, señalan que la pequeña iglesia sólo tenía una torre de adobe, ligeramente exenta (como ocurre con varias iglesias de la región) mientras que la nueva está adosada a la nave. Salvo una capilla de Sabaino, que tiene dos espadańas cortas, y la de Ayahuay (que no parece antigua), ninguna iglesia de esta provincia tiene dos torres.

\section{Marco geológico}

La localidad está asentada sobre un basamento de cuarcitas y areniscas cuarcíticas de la Formación Soraya, perteneciente al Neocomiano inferior del Cretácico inferior (Pecho, 1981: 24), sobre el que reposa un amplio rellano conformada por sedimentos cuaternarios de tipo glacio-aluvial o fluvioglaciares del Pleistoceno. También hay, en las cercanías, pequeńos afloramientos de andesita y andesita porfirítica de origen hipoabisal, posiblemente del Terciario medio a superior; de ellos provienen los soportes líticos de los litograbados de Matara. En medio de la meseta existía un pantano de origen glaciar, cuyo nivel de agua, gracias a un dique, fue elevado artificialmente, formando la actual laguna y un contexto paisajístico bastante llamativo.

\section{Antecedentes}

Son muy pocas las manifestaciones rupestres registradas hasta la fecha en la provincia de Antabamba. Con excepción de un petroglifo de figuración abstractageométrica, registrado junto a otros pictogramas en Huayllanqori (Carreño, 2020b: 131-132), todas corresponden a pictogramas.

Las expresiones rupestres más conocidas de esta provincia son las pinturas de Allhuanso, citadas por primera vez en el Diccionario arqueológico del Perú de C. García Rosell (1964?: 122), registradas también en 1967 por Ravines (INC, 1986: 13), en 1986 por Castro Tamayo (1987: 30) y, posteriormente, por Julinho Zapata en julio del 2000 y van Dalen (2015: 81-84). El inventario de Hostnig (2003:
29-36), además de las referencias de Allhuanso, incluye otros dos sitios con pictografías: Kentoqasa y Corredera. El detallado relevamiento arqueológico del valle de Mollebamba, realizado por van Dallen et al. (2016) no consigna ninguna expresión rupestre. Del mismo modo, no hay ninguna estación rupestre entre «un total de 66 sitios arqueológicos y 84 sectores de andenerías agrícola correspondiente a diferentes ocupaciones prehispánicas de la zona» registrados por Huarcaya Quispe (2020: 140) en esa misma cuenca. Tampoco aparecen manifestaciones rupestres en el primer inventario conocido de restos arqueológicos de Apurímac, realizado por Mejía Xespe en 1942 que consigna 17 lugares en Antabamba, todos considerados pre-inkas (en Carreño y Kalafatovich, 2008: 230).

\section{Los litograbados de la iglesia de Matara}

En visitas realizadas en mayo del 2008 y marzo del 2010, el autor identificó hasta nueve litograbados cubiertos por vegetación en los peldaños de la escalinata del arco de acceso al espacio eclesiástico, que comprende la iglesia colonial, un amplio atrio con un cerco perimétrico de adobe según el modelo tradicional coronado por una trama de adobes inclinados (figs. 4 y 5). En otra visita realizada en julio 2019, se constató que el hermoso arco colonial de piedra y adobe y su escalinata pétrea habían sido demolidos y reemplazados por antiestéticas construcciones en concreto (fig. 6); del mismo modo, de los nueve litograbados sólo quedaban dos; los demás habían desaparecido, no siendo ubicables entre los escombros de la «restauración» de la iglesia. Es probable que los sillares grabados hayan sido empleados como base para la nueva escalinata de concreto o de alguna de las nuevas construcciones que han invadido la plaza, o que hayan sido tirados junto al desmonte de la remodelación. Esta lamentable pérdida es una clara muestra de la ignorancia que prima entre las autoridades locales, que emprenden «modernizaciones» sin ningún criterio de conservación, constituyendo atentados que, al menos en teoría, constituyen delitos penales.

De los ejemplares desaparecidos, LgMA-1 era el de mejor diseño y fábrica: una espiral levógira de dos volutas con una cazoleta al centro y un gancho de sa- 


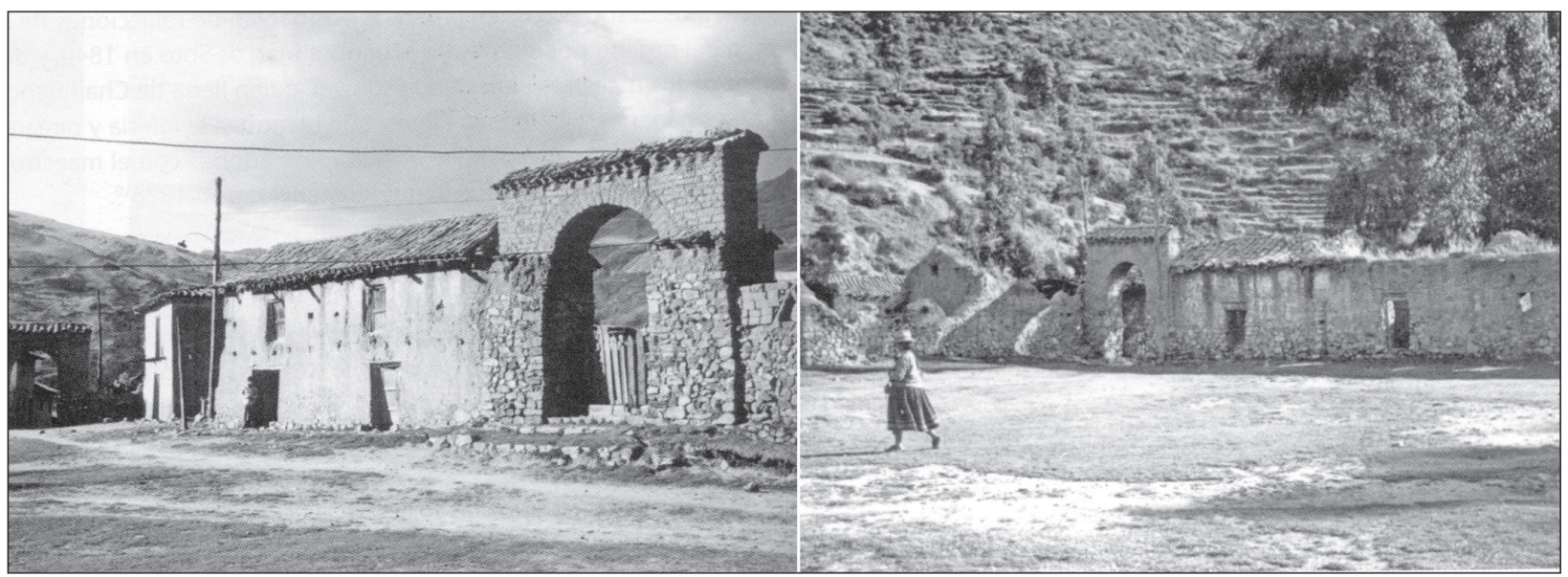

Fig. 4. Plaza con los dos arcos coloniales en fotos de los años 70 del siglo XX (tomado de Viñuales y Gutiérrez, 2014: 154)

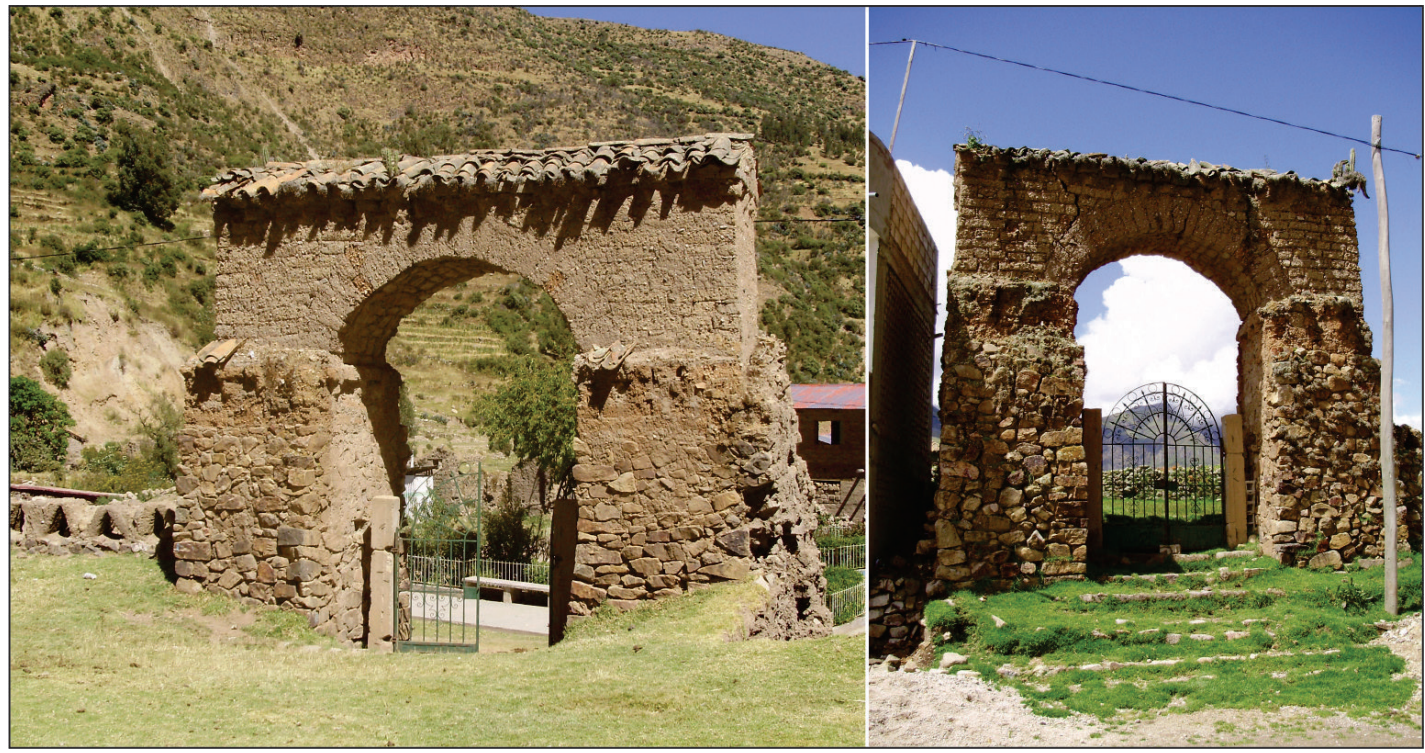

Fig. 5. El arco original de piedra $y$ adobe, en cuyos peldaños superiores de la escalinata se ubicaban los litograbados

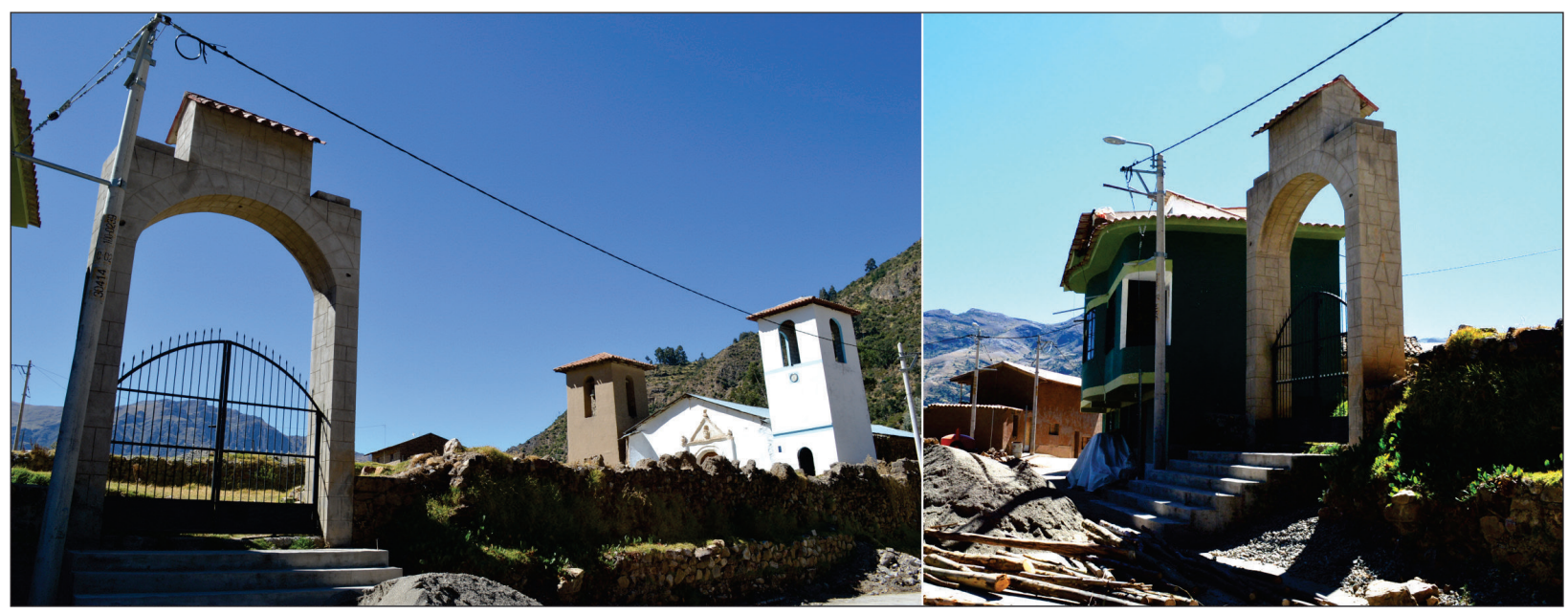

Fig. 6. El arco y la escalinata de concreto que reemplazaron a las estructuras originales de la época colonial 


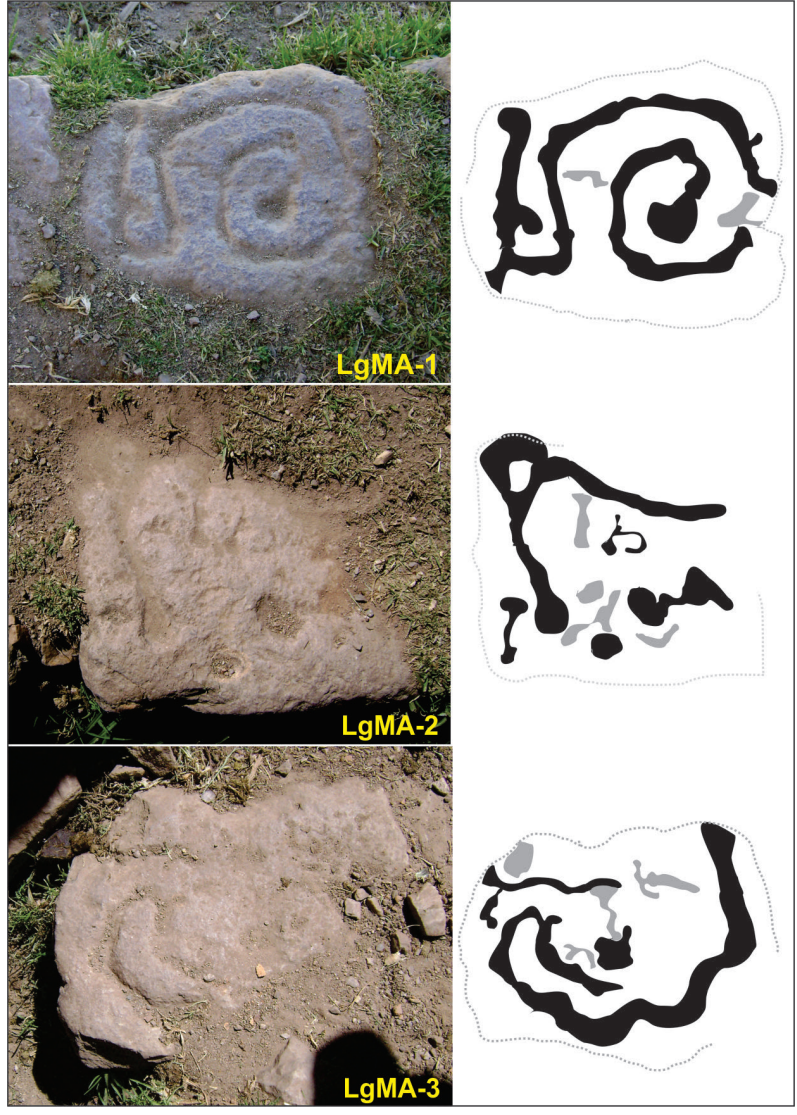

Fig. 7. Los tres litograbados mejor conservados, hoy desaparecidos

lida hacia el borde del sillar; el surco era ancho y pulido; otra característica de este grabado era su soporte lítico, el menos alterado de todos, es decir que la roca andesítica estaba en muy buen estado de conservación. LgMA-2 presentaba una configuración que recuerda a una $\mathrm{A}$, mostrando demás algunas cúpulas de rústico trazo (una al inicio del surco principal y otras aisladas). Del mismo modo, parece que LgMA3 fue parte de un diseño mayor en espiral, porque sus extremos desembocan en dos bordes opuestos del sillar; también existe una cúpula central de contorno irregular (fig. 7).

Los cuatro litos desaparecidos restantes mostraban diseños menos elaborados y estaban más desgastados (fig. 8). LgMA-4 era el pedazo de un grabado mayor también en espiral; quedaba lo que sería parte de una voluta o doble arco incompleto. LgMA-5 parecía igualmente una pieza seccionada con surcos en gancho concentrados en su parte inferior. LgMA-6, el más desgastado de todos, mostraba restos de surcos poco visibles que configuraban un amplio arco con

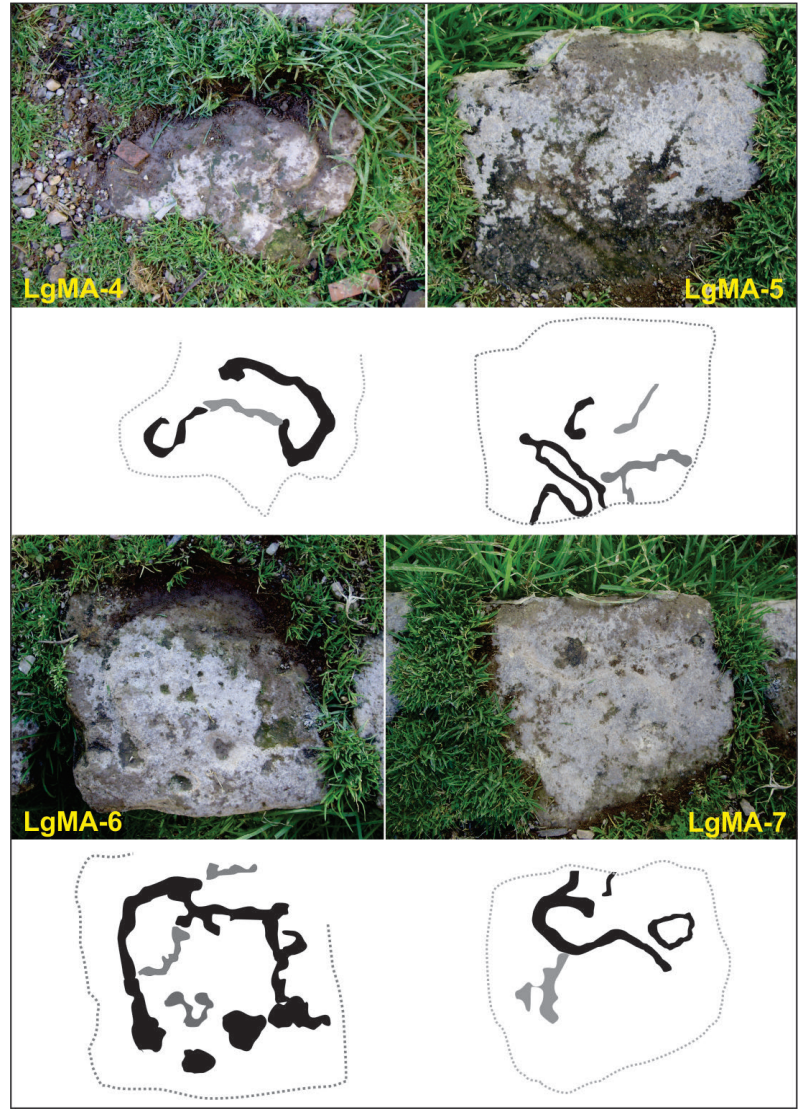

Fig. 8. Los otros cuatro litograbados desaparecidos que mostraban mayores signos de deterioro

varias tacitas muy irregulares. En LgMA-7 se percibían restos de un gancho bifurcado y de una cúpula; hay indicios que hacen pensar en que este ejemplar era también parte de una espiral mayor.

De los dos ejemplares supérstites (fig. 9), LgMA8 , en un bloque de andesita bastante alterada, presenta un diseño intrincado cuya parte central deja vislumbrar una espiral modificada por varios surcos adicionales; es el único lito colocado en posición vertical; es notorio que se trata, como en todos los casos de este sitio, de un bloque cortado cuyos surcos continuaban en la parte superior. LgMA-9 deja ver un diseño vagamente triangular con dos líneas divergentes y una barra de unión, asemejándose a una letra A, con ganchos en sus extremidades y por lo menos una cúpula mal pergeñada; tiene cierto parecido con LgMA-2.

Como se indicó, el soporte lítico corresponde a andesitas no volcánicas sino del tipo hipoabisal, es decir de lava que no llegó a superficie, sino que se consolidó a cierta profundidad. La roca en estos dos 


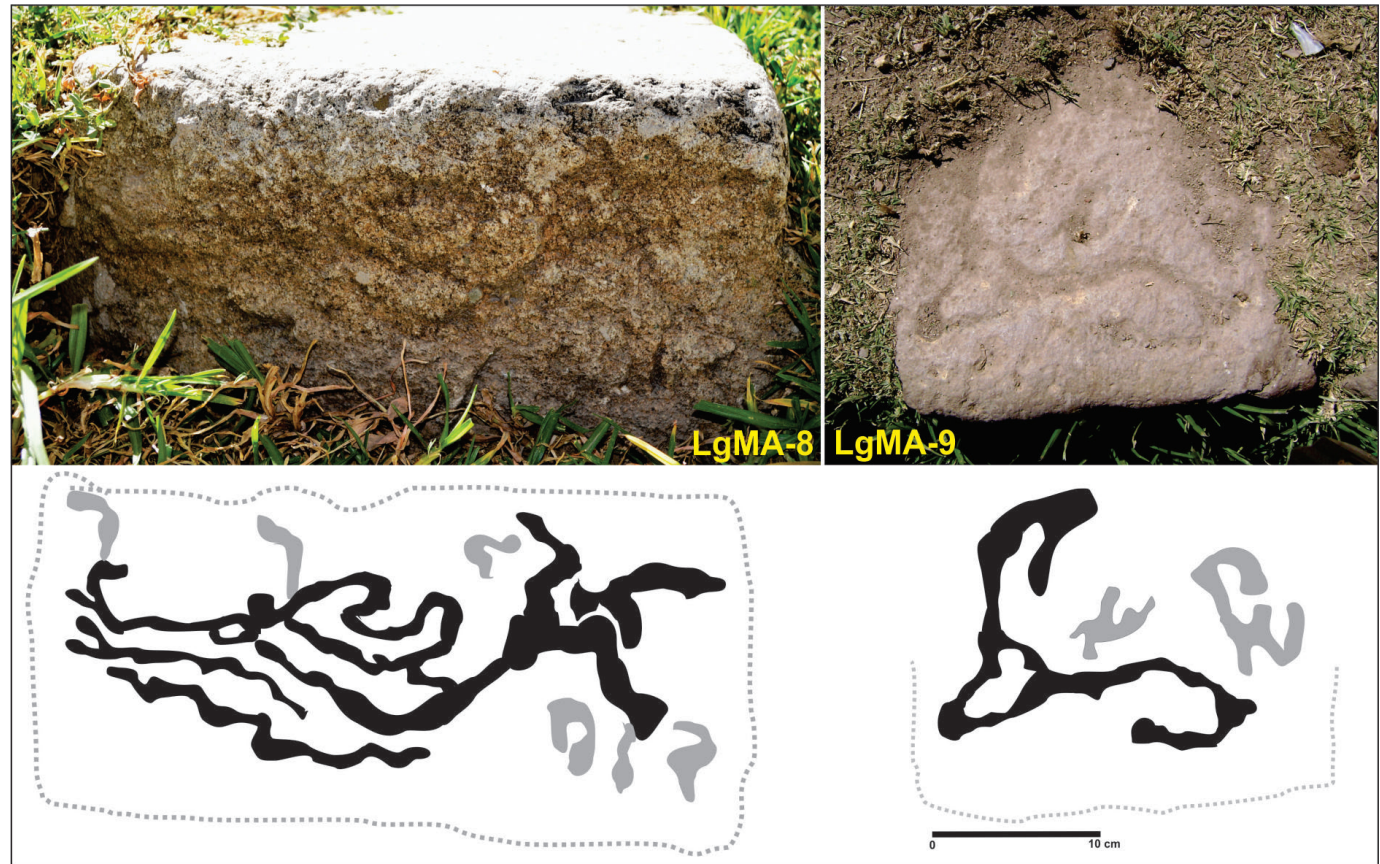

Fig. 9. Las únicas dos insculturas sobrevivientes (julio 2019) ejemplares ha sufrido alteración química por intemperismo, produciendo una pátina blanquecina en el primer caso, y rojiza en el segundo.

\section{Discusión}

La discontinuidad de los surcos, evidente en varios especímenes, indicaría que, en la mayoría de casos, los litograbados de Matara son fragmentos de otros grabados mayores y que fueron labrados a manera de sillares para ser acomodados como parte de los peldaños. Esto evidencia que se trata de un contexto secundario colonial, por lo cual poco o nada puede decirse acerca de la asociación cultural original de estos grabados. Es probable que los estos litograbados hayan sido parte del ushnu inka, o de algún otro adoratorio precolombino, sobre el cual se edificó el complejo eclesiástico colonial. La hipótesis que se plantea apunta a que se trató originalmente de petroglifos que fueron luego cortados para elaborar mampuestos. De ello resulta que los petroglifos originales fueron pre-inkas, de algún grupo no identificable, pues la iconografía involucra figuras genéricas, de uso por decir universal (espirales, ganchos, tacitas), sin figuraciones precisas y de trazo no muy cuidadoso.

La tosquedad del trazo y los diseños nos remitiría a un origen muy antiguo (tal vez incluso del
Arcaico) y que fueron parte de petroglifos incisos en bloques andesíticos sueltos. La práctica de fabricar sillares a partir de petroglifos más antiguos fue al parecer una práctica más o menos común en tiempos del Tardío. Más adelante, como es sabido, estas construcciones inkas fueron usadas como canteras, por lo que esos bloques fueron luego incorporados como sillares y baldosas a paramentos coloniales. Existen varios ejemplos de ello en iglesias y casonas de los departamentos de Cusco (San Jerónimo, Oropesa, Andahuaylillas, Chinchero, Limatambo, Urcos... y en el centro histórico de la ciudad capital) y Puno (Pucara). El hecho de que en Matara y en las localidades mencionadas, las canaletas o surcos aparecen, sin excepción, interrumpidos en los bordes prueba dicho aserto, pues denotan que tales surcos se prolongaban más allá del límite impuesto por el labrado de los mampuestos.

La existencia de cúpulas (a pesar de su tosca factura), tanto conectadas a los surcos como aisladas, hace pensar que los petroglifos originales pudieron estar destinados a ritos votivos con líquidos, función que comúnmente se atribuye a grabados con canales y tacitas, no sólo del ámbito andino sino de muchos sitios rupestres de otros lugares. Obviamente esta eventual función se perdió cuando los petroglifos fueron transformados en litograbados y colocados en la escalinata, algunos en posición vertical. 
Cualquier eventual intento de correlación/interpretación simbólica se complica más si tenemos en cuenta que, hasta donde lo muestra la literatura disponible, ningún otro petrograbado de este tipo ha sido registrado anteriormente en la provincia de Antabamba. EL petroglifo de Huayllanqori es de un estilo completamente distinto y de un diseño y factura técnicamente más primitivos. Como ya se refirió, todos los sitios rupestres conocidos de Antabamba contienen sólo pictogramas. En consecuencia, el de Huayllanqori y los de Matara serían los primeros grabados identificados de esta provincia. Las pocas expresiones rupestres inventariadas en Antabamba no permiten establecer eventuales «estilos» iconográficos. Los ejemplares de Matara no parecen responder a una iconografía determinada, pues los trazos son, por decirlo de algún modo, inorgánicos, con figuras caóticas, donde sólo resaltan las espirales poco desarrolladas, y sabemos muy bien, como ya se indicó, que las espirales son figuras de ocurrencia universal, por lo que no ayudan mucho para establecer filiaciones.

De otro lado, la zona ha sido asiento de diferentes naciones, desde el Arcaico. En el Intermedio Tardío hubo incluso una corta ocupación chanka, antes de su expulsión del espacio apurimeño, una vez derrotados por el gran emperador Pachakúteq cuando trataron de asaltar el Cusco. La falta de dataciones absolutas, de una caracterización iconográfica de las culturas preinkas que se desarrollaron en este ámbito (de los aymaraes - citados en diversas crónicas y para quienes van Dalen sólo ha determinado un estilo arquitectónico- y los umasuyus, tal vez de los qotanera u otros), impide establecer criterios válidos para determinar cualquier eventual filiación de estos grabados.

Por la similitud con las andenerías de Caraybamba, que van Dalen (2009: 268) ha estudiado con detalle, se podría plantear que las de Huaquirca, ubicadas en la ladera opuesta, y las menos amplias y desarrolladas de Matara (debido seguramente a una mayor disponibilidad de terrenos de cultivo en área plana que no necesitaba mayor acondicionamiento), fueron construidas y explotadas durante el Intermedio Tardío y el Tardío, por lo que una posible asociación de los litograbados con la cultura o "nación aymara» (o aymaraes) y/o la inka podría ser factible, aunque no se descarta que los petrograbados originales sean más antiguos.
Queda, así mismo, por dilucidar el por qué todos estos litograbados fueron instalados en los peldaños de la escalinata de acceso al atrio y no, por ejemplo, en la entrada del templo o en sus muros y contrafuertes. En la iglesia de Turpay, en el vecino valle de Vilcabamba (provincia de Grau), por ejemplo, un litograbado precolombino fue colocado al pie del ara. En la catedral del Cusco, varios litograbados similares forman también parte de escalinatas del coro (Carreño, 2020a: 212-214), aunque otros, aislados, se observan en muros de iglesias y casonas coloniales.

Empero, por el momento, todo queda en el plano de las hipótesis; en el estado actual del conocimiento, al no haber estudios más precisos sobre las culturas pre-inkas ni los suficientes sobre la ocupación inka en Antabamba, resulta casi imposible establecer filiaciones culturales válidas para estos litograbados, lamentablemente desaparecidos hoy en su mayoría, gracias a la necedad de sus autoridades locales y a la indiferencia o falta de presencia efectiva del ministerio correspondiente.

\section{Agradecimiento}

A Susana Kalafatovich, por su apoyo en el trabajo de campo.

\section{Referencias bibliográficas}

Carreño Collatupa, Raúl (2020a). Arte rupestre de origen precolombino en la Catedral del Cusco - Perú. Revista Cuadernos de Arte Prehistórico, No 9, pp. 206-232.

Carreño Collatupa, Raúl (2020b). La estación rupestre de Huayllanqori, provincia de Antabamba (Apurímac, Perú). Antrope. Arqueologias e seus contextos, № 12, pp. 118-138.

Carreño, Raúl; Susana Kalafatovich (2008). Visión de Apurimac. Cusco: GVC-Proyecto Arguedas.

Castro Tamayo, Lucio (1987). Antabamba a través de la historia. Tesis para optar al título de Licenciado en Historia. Cusco: Universidad Nacional de San Antonio Abad.

Dirección Nacional Técnica de Demarcación Territorial (2012). Estudio de diagnóstico y zonificación para el tratamiento de la demarcación territorial de la provincia de Antabamba. Abancay: DNTDT. 
García Rosell, César (1964?). Diccionario arqueológico del Perú. Lima: se.

Garcilaso de la Vega, Inca (1609). Primera parte de los Commentarios reales, que tratan del origen de los Incas, reyes que fveron del Perv.... Lisboa: Officina de Pedro Crasbeeck.

Gose, Peter (2004). Aguas mortiferas y cerros hambrientos. Ritos agrarios y formación de clases en un pueblo andino. Quito: Ediciones Abya Yala.

Hostnig, Rainer (2003). Arte rupestre del Perú. Inventario nacional. Lima: CONCYTEC.

Huarcaya Quispe, Francisco (2020). Registro y ubicación de sitios arqueológicos en la cuenca del distrito de Juan Espinoza Medrano - Mollebamba - Provincia Antabamba - Apurímac. En Pieter van Dalen (editor), Libro de resúmenes del I Congreso Internacional de Arqueología de Apurimac, pp. 138-146. Lima: FEDIRAL-Juan Gutenberg editores-impresores.,.

Instituto Nacional de Cultura (1986). Arte rupestre del Perú. Inventario general (Primera aproximación). Compilación de R. Ravines, con la colaboración de F. Iriarte y A. Matos. Lima: INC.

Instituto Nacional de Estadísticas E Informática (2018). Apurimac - Resultados definitivos. Censos nacionales 2017. Lima: INEI.

Pecho Gutiérrez, Víctor (1981). Geología de los cuadrángulos de Chalhuanca, Antabamba y Santo Tomás. Boletín No 35. Lima: INGEMMET.
Sánchez Garrafa, Rodolfo (1999). Wakas y Apus de Pamparaqay. Estructuras simbólicas en la tradición oral de Grau-Apurimac. Lima: Cotimice editores.

Van Dalen, Pieter (2009). Andenerías y asentamientos tardíos en Caraybamba, Apurímac. Investigaciones Sociales, vol. 13 No 22, pp. 247-270.

DOI: https://doi.org/10.15381/is.v13i22.7251

Van Dalen, Pieter (2015). Allwanso, un sitio con pinturas rupestres tardías en Huaquirca, Antabamba, región Apurímac. En Alberto Bueno, Pieter van Dalen, Yuri Cavero, Hans Grados y Roy Lazo (editores), Actas de Ponencias del V Simposio Nacional de Arte Rupestre SINAR "Eloy Linares Málaga», pp. 77-88. Lima: Universidad Nacional Mayor de San Marcos.

Van Dalen, Pieter; Hamilton Obregón; Angélica López y Joe Huamaní (2016). Arqueología de la cuenca del río Mollebamba, Antabamba-Apurímac. Arqueología y Sociedad, No 32, pp. 387-450.

https://revistasinvestigacion.unmsm.edu.pe/index. php/Arqueo/article/view/13344

Villanueva Urteaga, Horacio (1982). Cuzco 1689, documentos. Economía y sociedad en el sur andino. Archivos de Historia andina No 1. Cusco: CERA Bartolomé de las Casas.

Viñuales, Graciela; Gutiérrez, Ramón (2014). Historia de los pueblos de indios de Cusco y Apurimac. Lima: CEDODAL-Universidad de Lima-Fondo editorial. 